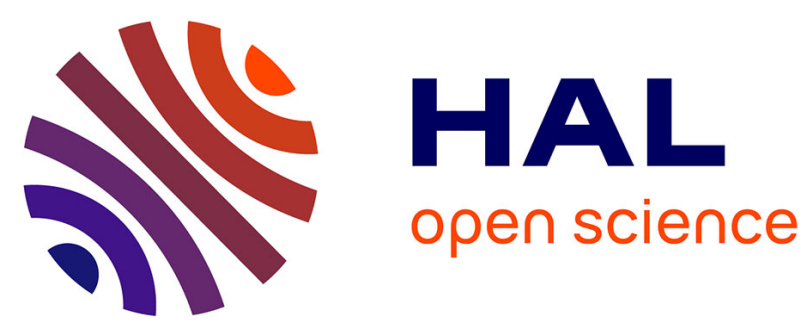

\title{
Interface Properties of GaP/Si Heterojunction Fabricated by PE-ALD
}

Alexander S. Gudovskikh, Alexander Uvarov, Ivan A. Morozov, Artem

Baranov, Dimitry Kudryashov, Kirill S. Zelentsov, Alexandre Jaffré, Sylvain

Le Gall, Arouna Darga, Aurore Brézard-Oudot, et al.

\section{To cite this version:}

Alexander S. Gudovskikh, Alexander Uvarov, Ivan A. Morozov, Artem Baranov, Dimitry Kudryashov, et al.. Interface Properties of GaP/Si Heterojunction Fabricated by PE-ALD. physica status solidi (a), 2019, 216 (10), pp.1800617. 10.1002/pssa.201800617 . hal-01943257

\section{HAL Id: hal-01943257 \\ https://hal.science/hal-01943257}

Submitted on 12 Mar 2020

HAL is a multi-disciplinary open access archive for the deposit and dissemination of scientific research documents, whether they are published or not. The documents may come from teaching and research institutions in France or abroad, or from public or private research centers.
L'archive ouverte pluridisciplinaire HAL, est destinée au dépôt et à la diffusion de documents scientifiques de niveau recherche, publiés ou non, émanant des établissements d'enseignement et de recherche français ou étrangers, des laboratoires publics ou privés. 


\title{
Interface Properties of GaP/Si Heterojunction Fabricated by PE-ALD
}

\author{
Alexander S. Gudovskikh,* Alexander V. Uvarov, Ivan A. Morozov, \\ Artem I. Baranov, Dmitry A. Kudryashov, Kirill S. Zelentsov, Alexandre Jaffré, \\ Sylvain Le Gall, Arouna Darga, Aurore Brezard-Oudot, and Jean-Paul Kleider
}

The properties of $n-\mathrm{GaP} / \mathrm{p}-\mathrm{Si}$ interface as well as their influence on solar cell performance are studied for GaP layers grown by low-temperature $\left(380^{\circ} \mathrm{C}\right)$ plasma-enhanced atomic layer deposition (PE-ALD). The influence of different plasma treatments and RF power values are explored. The increase of RF power leads to a growth transition from amorphous (a-GaP) to microcrystalline $\mathrm{GaP}(\mu \mathrm{c}-\mathrm{GaP})$ with either amorphous-GaP/Si or epitaxial-GaP/Si interface, respectively. However, when continuous hydrogen plasma is used the amorphous-GaP/Si interface exhibits better photovoltaic performance compared to the epitaxial one. Values of open circuit voltage, $V_{\text {oc }}=0.45-0.55 \mathrm{~V}$ and internal quantum efficiencies, IQE $>0.9$ are obtained for amorphous-

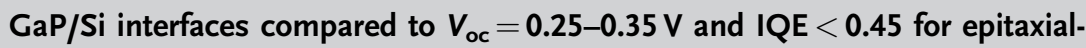
$\mathrm{GaP} / \mathrm{Si}$ interfaces. According to admittance spectroscopy and TEM studies the near-surface $(30-50 \mathrm{~nm})$ area of the Si substrate is damaged during growth with high RF power of hydrogen plasma. A hole trap at the level of $E_{V}+(0.33 \pm 0.02) e V$ is detected by admittance spectroscopy in this damaged $\mathrm{Si}$ area. The damage of $\mathrm{Si}$ is not observed by TEM when the deposition of the structures with epitaxial-GaP/Si interface is realized by a modified process without hydrogen plasma indicating that the damage of the nearsurface area of $\mathrm{Si}$ is related to hydrogen plasma interaction.

\section{Introduction}

Combination of III-V compounds with silicon is of great interest for the development of new optoelectronic devices, in particular

Prof. A. S. Gudovskikh, A. V. Uvarov, I. A. Morozov, Dr. A. I. Baranov, Dr. D. A. Kudryashov, K. S. Zelentsov

St. Petersburg National Research Academic University RAS

194021 St. Petersburg, Russia

E-mail: gudovskikh@spbau.ru

A. Jaffré, Dr. S. Le Gall, Dr. A. Darga, A. Brezard-Oudot, Prof. J.-P. Kleider GeePs, Group of Electrical Engineering - Paris

CNRS

CentraleSupélec

Univ. Paris-Sud

Université Paris-Saclay Sorbonne Universités

UPMC Univ Paris 06, 91192 Gif-sur-Yvette Cedex, France

The ORCID identification number(s) for the author(s) of this article can be found under https://doi.org/10.1002/pssa.201800617.

DOI: 10.1002/pssa.201800617 multijunction solar cells. One of the best candidates for the nucleation and buffer layer to be grown on Si surfaces for further III-V materials growth is $\mathrm{GaP}$, which has the smallest lattice mismatch to Si among all III-V binary compounds (0.4\%). GaP with a band gap of $2.26 \mathrm{eV}$ could also be used as a wide band gap emitter or window layer for Si-based bottom cells in multijunction solar cells.

The band discontinuity of the $\mathrm{GaP} / \mathrm{Si}$ interface was widely studied theoretically $^{[1,2]}$ and experimentally ${ }^{[3-5]}$ and the estimated values for the conduction and valence band offset are within the range of $0.09-0.35 \mathrm{eV}$ and $0.8-1.05 \mathrm{eV}$, respectively. Despite some spreading in the determined values the valence band offset $\left(\Delta E_{\mathrm{V}}\right)$ is commonly accepted to be much larger compared to that of the conductance band one. Significant valence band offset at the $\mathrm{GaP} / \mathrm{Si}$ interface leads to formation of high potential barrier at the interface with p-type $\mathrm{GaP}$ that causes the limitation of the hole transport. ${ }^{[6]}$ In contrast, the lower conduction band offset does not lead to formation of any potential barriers at the interface with n-type $\mathrm{GaP}$ layers, which could affect the electron transport. Thus n-GaP/n-Si isotype or n-GaP/p-Si anisotype heterostructures are of main interest for solar cell applications. However, electronic properties of the $\mathrm{GaP} / \mathrm{Si}$ interface, in particular, interface states densities strongly depend on the GaP growth conditions including silicon surface pre-treatment, growth temperature, etc. The growth of polar III-V materials on nonpolar Si substrates faces several important issues. The nucleation phase of III-V materials may give rise to bonds between two group-III or two group-V atoms. These bonds between similar atoms act as a boundary between two single crystalline domains opposite in phase (antiphase boundaries), which could propagate along the direction of growth. Another problem is related to elastic stresses in the growing layer, which lead to the appearance of dislocations. This problem is associated primarily with the high temperatures required for the growth due to different coefficients of thermal expansion in silicon and GaP. Finally, the use of high temperatures leads to inter-diffusion of group-III and $-\mathrm{V}$ atoms into $\mathrm{Si}$ and opposite, which act as dopants affecting the electrical properties of heterojunctions. The epitaxial growth 
of GaP, which normally requires high temperature at least during the annealing step for Si deoxidation and surface reconstruction could affect the electronic properties at the interface as well as properties of Si substrates. ${ }^{[7]}$ Lifetime degradation in the volume of Si substrates (for depth of more than 20 microns) was observed after metalorganic vapor-phase epitaxy (MOVPE) of $\mathrm{GaP}$ or $\mathrm{Si}$ substrate annealing in the MOVPE chamber, which was associated with fast diffusion of species. ${ }^{[8]}$ In case of molecular beam epitaxy (MBE) the growth of GaP occurs at lower temperatures (500$600^{\circ} \mathrm{C}$ ) but still a high temperature Si substrate pre-treatment $\left(800-900^{\circ} \mathrm{C}\right)$ in high vacuum conditions of the MBE chamber is required. A significant lifetime degradation of Si substrates due to high temperature annealing in the MBE chamber was reported in ref. [9]. Also a formation of thin $\approx 30 \mathrm{~nm}$ defective layer in Si near to the GaP interface was detected. ${ }^{[6]}$ This defective layer attributed to the diffusion process during the GaP growth leads to significant reduction of solar cell performance for anisotype $n-\mathrm{GaP} / \mathrm{p}-\mathrm{Si}$ heterojunctions due to strong recombination in the space charge region. An intentional phosphorous diffusion in $\mathrm{p}$-Si prior to $\mathrm{n}$ $\mathrm{GaP}$ growth improves the performance of the $\mathrm{n}-\mathrm{GaP} / \mathrm{n}-\mathrm{p}-\mathrm{Si}$ heterostructure because the space charge region is moved away from defective layer. ${ }^{[6]}$ However silicon solar cells with $\mathrm{GaP}$ window layers fabricated by MOVPE of $n-G a P$ on $n-p \quad S i$ homojunctions with a high temperature $\left(750-1050{ }^{\circ} \mathrm{C}\right)$ surface reconstruction step ${ }^{[10]}$ demonstrated a high surface recombination velocity $\left(10^{5} \mathrm{~cm} \mathrm{~s}^{-1}\right)$ at the $\mathrm{GaP} / \mathrm{Si}$ interface estimated by the analysis of quantum efficiency spectra. Strong recombination at the interface was explained by the high density of interface states due to antiphase boundaries in the GaP layer.

In this paper, we explore the interface properties of $\mathrm{GaP} / \mathrm{Si}$ heterojunctions fabricated by a low temperature (less than $400^{\circ} \mathrm{C}$ ) technological approach for the growth of III-V compounds on Si substrates using the plasma-enhanced atomic layer deposition (PE-ALD) technique. The process consists of alternatively changing the phosphorus and gallium atom source flows providing the growth of one monolayer by cycle. This new technological approach was recently developed for the growth of amorphous and microcrystalline GaP layers. ${ }^{[11]}$ The transition from amorphous to microcrystalline structure has been obtained by the increase of the RF power. However, for higher RF power process an accumulation of the phosphorous at the deposition chamber walls was observed. The excess phosphorous in the chamber interacts with Ga precursors perturbing the ALD mode. An additional high RF power hydrogen plasma etching step after $P$ deposition should be used to minimize this negative effect. ${ }^{[10]}$ On the other hand hydrogen plasma could provide acceptor deactivation in $\mathrm{B}$ doped p-type $\mathrm{Si}^{[12]}$ and even damage the $\mathrm{Si}$ surface. ${ }^{[13]}$ Our previous study demonstrated that no significant influence of the growth process on the volume properties of silicon wafers could be observed by space charge capacitance techniques. ${ }^{[14]}$ However, to our knowledge the interface properties of $\mathrm{GaP} / \mathrm{Si}$ heterojunctions formed by low temperature plasma-assisted technique were not studied so far.

\section{Experimental Section}

$\mathrm{GaP}$ layers of $50 \mathrm{~nm}$ thickness were grown on p-type $(0.8-$ $1.2 \mathrm{ohm} \mathrm{cm}$ ) B-doped CZ Si substrates of (001) orientation with $4^{\circ}$ off cut toward [110]. Si wafers were cleaned by the Shiraki method $^{[15]}$ followed by an HF-dip removal of oxide prior to the $\mathrm{GaP}$ deposition. The PE-ALD process was realized at the temperature of $380^{\circ} \mathrm{C}$ using a conventional Oxford PlasmaLab 100 PECVD setup supplied by phosphine $\left(\mathrm{PH}_{3}\right)$ and trimethylgallium (TMG) lines for sources of phosphorus and gallium.

The process flow for different samples is presented by the sketches in Figure 1. First the deposition was performed with continuous $\mathrm{H}_{2}$ plasma discharge during the deposition and purge cycles. Two different modes of the deposition were used: i) with constant low RF power of $20 \mathrm{~W}$, which provides a growth of amorphous GaP films (a-GaP); ii) with pulsed RF power increase to $100 \mathrm{~W}$ during $\mathrm{Ga}$ and $\mathrm{P}$ deposition steps (4 and $2 \mathrm{~s}$, respectively) and during the hydrogen plasma treatment step $(7 \mathrm{~s})$, which was used after $\mathrm{P}$ deposition step to etch excess phosphorus accumulated at the chamber walls. The latter mode provides a growth of microcrystalline GaP ( $\mu \mathrm{c}-\mathrm{GaP})$. In both cases a growth rate of about one monolayer per cycle was reached. For more deposition details one can refer to ref. [11]. A combination of 3-5 nm a-GaP deposition with subsequent growth of $\mu \mathrm{c}-\mathrm{GaP}$ was also used (case (iii) in Figure 1).

Finally, to verify the influence of the hydrogen plasma on the interface properties a PE-ALD process without hydrogen plasma was performed. In this case a short pulse $(2 \mathrm{~s})$ of plasma (RF power of $200 \mathrm{~W})$ which content hydrogen was used for $\mathrm{PH}_{3}$ decomposition only, while deposition of Ga occurred due to thermal decomposition of TMG. Intermediate evacuation and $\mathrm{Ar}$ purge steps were introduced between $\mathrm{Ga}$ and $\mathrm{P}$ deposition steps to avoid gas mixture. An additional Ar plasma step (200 W, $15 \mathrm{~s}$ ) was used immediately before the TMG thermal decomposition step for surface activation. This additional step allows us to increase the growth rate form 0.5 to approximately one monolayer per cycle. The obtained GaP films had microcrystalline structure.

For n-type doping an additional step of highly diluted $\mathrm{SiH}_{4}$ $(0.1 \%)$ was introduced. Incorporation of $\mathrm{Si}$ and high electron concentration $\left(>10^{18} \mathrm{~cm}^{-3}\right)$ in GaP layers were confirmed by glow discharge optical emission spectroscopy and electrochemical-CV measurements (ECV), respectively. ${ }^{[16]}$ The ECV profile

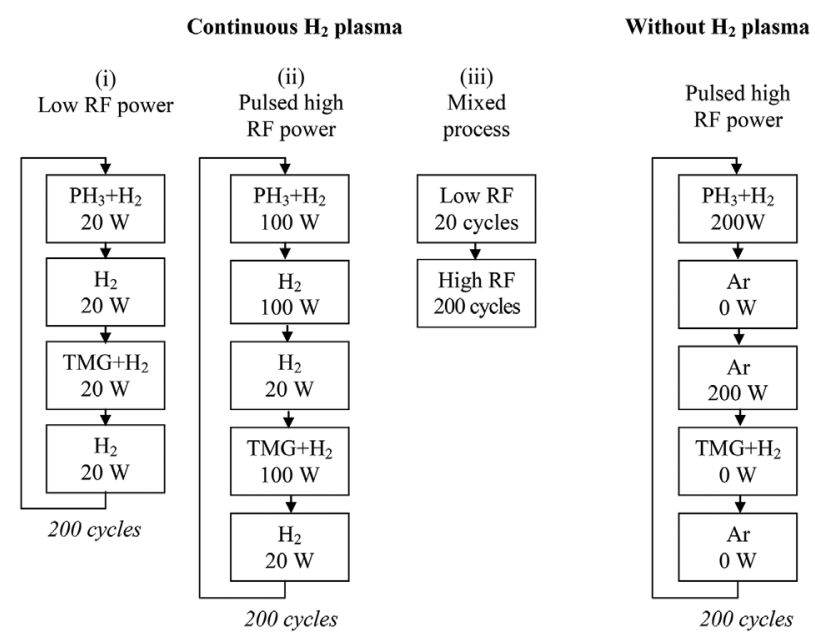

Figure 1. Sketches of the process flow for different samples. 
measured for an Si doped GaP layer deposited on n-type Si wafer is presented in Figure 2.

Structural properties of the $\mathrm{GaP} / \mathrm{Si}$ interface were studied by transmission electron microscopy (TEM) (JEOL JEM 2100F) with $200 \mathrm{kV}$ acceleration voltages.

$\mathrm{Ti} / \mathrm{Ag}$ or $\mathrm{Au} / \mathrm{Ge}$ grid and full metal ohmic contacts were formed to the $\mathrm{n}-\mathrm{GaP}$ layer to study photoelectrical and electrical properties, respectively, of $\mathrm{n}-\mathrm{GaP} / \mathrm{p}$-Si heterostructures. Indium ohmic contacts were formed to the back side of $\mathrm{p}$-Si. Standard $I-V$ curves under AM1.5G simulator (Abet Technology) were measured using a Keithley 2400 source-meter. Spectral dependence of quantum efficiency was recorded using a Solar Laser M266 monochromator supplied by a halogen lamp, a Si reference photodiode and a Stanford Research SR 830 lock-in amplifier.

Hall measurements were performed using an Ecopia HMS3000 Hall measurement system with 0.55 Tesla permanent magnet. Four indium contacts with Van der Pauw geometry were formed on the top GaP surface of $\mathrm{n}-\mathrm{GaP} / \mathrm{p}$-Si heterostructures.

Space charge capacitance techniques as capacitance-voltage measurements $(C-V)$ and admittance spectroscopy measurements (capacitance and conductance vs. temperature and frequency) were performed using an Agilent 4980A LCR meter and a Janis VPF 100 liquid nitrogen cryostat.

\section{Results}

The TEM cross section images of $\mathrm{GaP} / \mathrm{Si}$ interfaces for $\mathrm{GaP}$ grown with continuous hydrogen plasma are presented in Figure 3. In case of a-GaP growth on $\mathrm{Si}$ (occurring at low $\mathrm{RF}$ power) the interface has a sharp border between amorphous $\mathrm{GaP}$ and crystalline Si (Figure 3a). The same sharp amorphous interface is observed for the sample started with thin $(5 \mathrm{~nm})$ a$\mathrm{GaP}$ layer and continued by growth of $\mu \mathrm{c}-\mathrm{GaP}$ (Figure $3 \mathrm{~b}$ ).

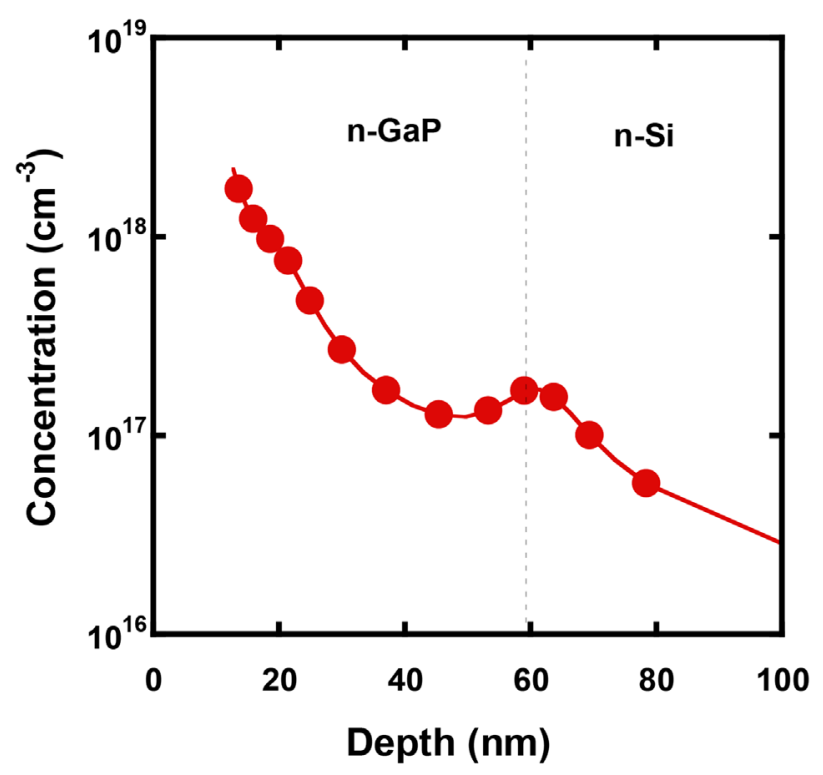

Figure 2. ECV electron concentration profile of an Si doped n-GaP layer deposited on $\mathrm{n}$-type Si.
However in case of direct $\mu \mathrm{c}-\mathrm{GaP}$ growth on the Si surface, the interface between $\mathrm{GaP}$ and $\mathrm{Si}$ can not be easily distinguished (Figure 3c). A special test structure was grown to study the $\mu \mathrm{c}$ $\mathrm{GaP} / \mathrm{Si}$ interface. Here the growth on Si surface was started with $3 \mathrm{~nm}$ of $\mu \mathrm{c}-\mathrm{GaP}$ followed by the growth of a thin $(5 \mathrm{~nm})$ Si layer. The epitaxial conformal growth of GaP at least for the first $3 \mathrm{~nm}$ was confirmed by TEM presented in Figure 3e. The Fourier filtering applied for the same area gives an evidence of the epitaxial growth (Figure 3e). Smooth interface between the epitaxial GaP (epi-GaP) layer and the amorphous Si indicates that PE-ALD allows us to obtain conformal 2D-growth without island formation on the Si substrate surface (3D-growth).

A new PE-ALD process using high RF power without hydrogen plasma also allows us to grow microcrystalline $\mathrm{GaP}$ on Si (Figure 3d). Analysis of the TEM images using Fourier filtering demonstrates that initial epitaxial growth of $\mathrm{GaP}$ also occurs in this case (Figure 3f). Few nanometers of $\mathrm{GaP}$ are grown epitaxially, while $\mathrm{GaP}$ crystallites then become disoriented.

Photoelectrical and electrical properties of $n-\mathrm{GaP} / \mathrm{p}-\mathrm{Si}$ heterojunctions fabricated using continuous hydrogen plasma strongly depend on the initial growth process. When growth is started by a low RF power process, which provides amorphous $\mathrm{GaP}$ at the interface, the $I-V$ curves under AM1.5G exhibit relatively high value of open circuit voltage $\left(V_{O C}\right)$ being in the range of $0.45-0.55 \mathrm{~V}$ (Figure $4 \mathrm{a}$ ) independent on subsequent a$\mathrm{GaP}$ or $\mu \mathrm{c}-\mathrm{GaP}$ growth. In this case $V_{\mathrm{OC}}$ is mostly limited by the low bulk minority carrier lifetime of used $\mathrm{Si}$ wafers and recombination at the back contact. It is demonstrated by spectra of internal quantum efficiency (IQE), which drop in the long wavelength region (Figure 4b). However when the growth is started by a high RF power process with hydrogen plasma, which provides epitaxial GaP interface (Figure $3 \mathrm{e}$ ), $V_{\mathrm{OC}}$ is found to be in the range of $0.25-0.35 \mathrm{~V}$, which is significantly lower compared to that of the amorphous GaP interface (Figure 4a). In the same time, the short circuit current density and IQE values in the whole spectral range are also considerably low (Figure 4b). This difference is obviously caused by strong recombination losses for the heterojunctions with epi-GaP interface obtained with hydrogen plasma. A high defect density is expected in the space charge region, which could be located either at the $\mathrm{GaP} / \mathrm{Si}$ interface or in Si near to the surface. In contrast, for the epitaxial GaP interface obtained without hydrogen plasma (Figure $3 \mathrm{f}$ ) the $\mathrm{GaP} / \mathrm{Si}$ structures demonstrate a value of $V_{\mathrm{OC}} \geq 0.45 \mathrm{~V}$ under AM1.5G simulator ( $I-V$ is not presented). Thus a-GaP interface obtained with hydrogen plasma of low RF power and epi-GaP interface obtained without hydrogen plasma provide considerably lower recombination rate at the $\mathrm{GaP} / \mathrm{Si}$ boundary compared to heterostructures with epi-GaP interface fabricated with high RF power hydrogen plasma step.

Another characteristic difference between those two groups of samples was observed in the lateral conductivity of $n-\mathrm{GaP} / \mathrm{p}-\mathrm{Si}$ heterostructures measured between two planar ohmic contacts deposited on the top of n-GaP layer (Figure 5a). Indeed, a high lateral conductivity, which is few orders of magnitude higher compared to that of single GaP layer, with a weak temperature dependence (activation energy $<0.1 \mathrm{eV}$ ) was previously observed for $\mathrm{n}-\mathrm{GaP} / \mathrm{p}$-Si heterostructures with a-GaP interface (followed by growth of a-GaP or $\mu \mathrm{c}-\mathrm{GaP}$ layers). It was explained by the 


\section{ADVANCED
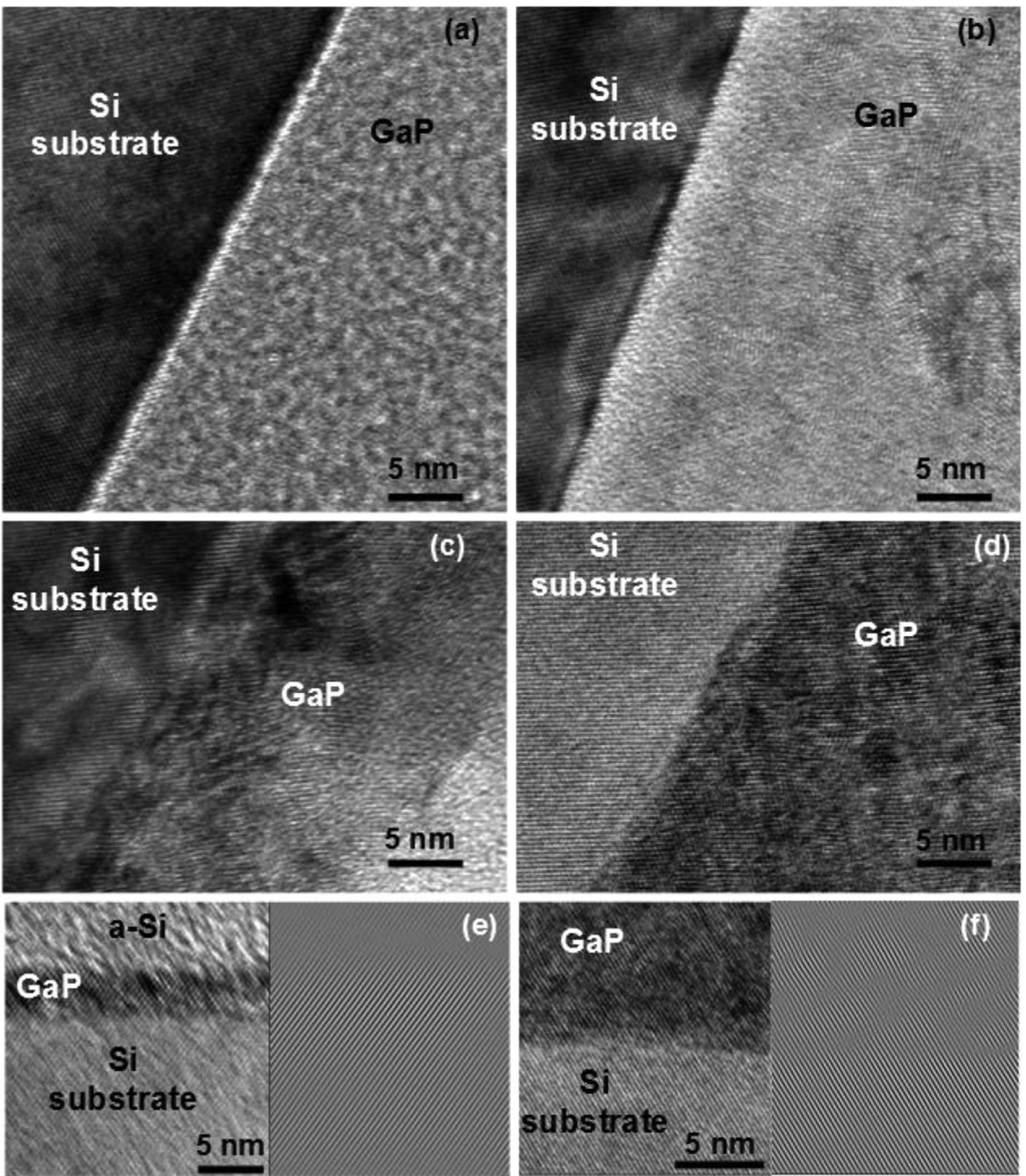

Figure 3. TEM cross section bright-field images of $\mathrm{GaP} / \mathrm{Si}$ interfaces a-GaP/Si (a), $\mu \mathrm{c}-\mathrm{GaP} /(5 \mathrm{~nm}) \mathrm{a}-\mathrm{GaP} / \mathrm{Si}$ (b), $\mu \mathrm{c}-\mathrm{GaP} / \mathrm{Si}(\mathrm{c}), \mathrm{a}-\mathrm{Si} /(3 \mathrm{~nm}) \mathrm{epi}-\mathrm{GaP} / \mathrm{Si}$ test structure (e) and epi-GaP produced without hydrogen plasma ( $d$ and f). A Fourier filtering of TEM images (e and f) is presented on the right side.

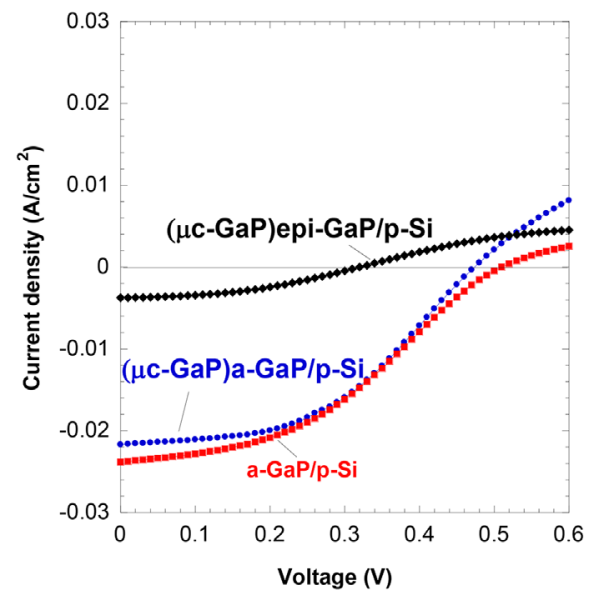

(a)

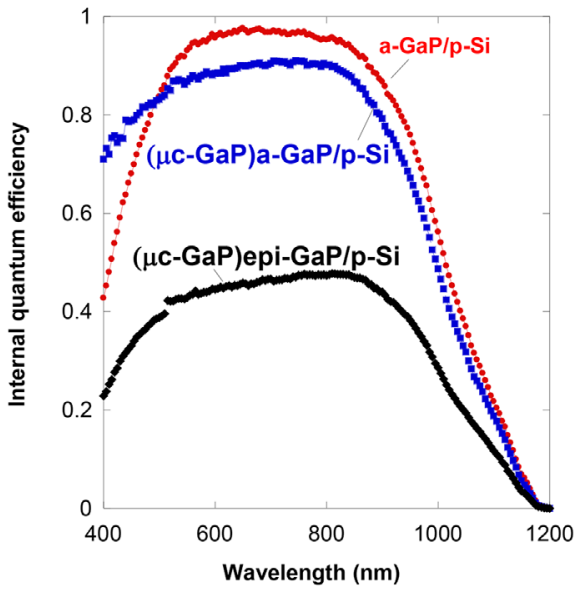

(b)

Figure 4. I-V curves under AM I.5G (a) and IQE (b) for $n-G a P / p-S i$ heterostructures with a-GaP (a-GaP and $\mu c-G a P$ layer) and epi-GaP interfaces. 


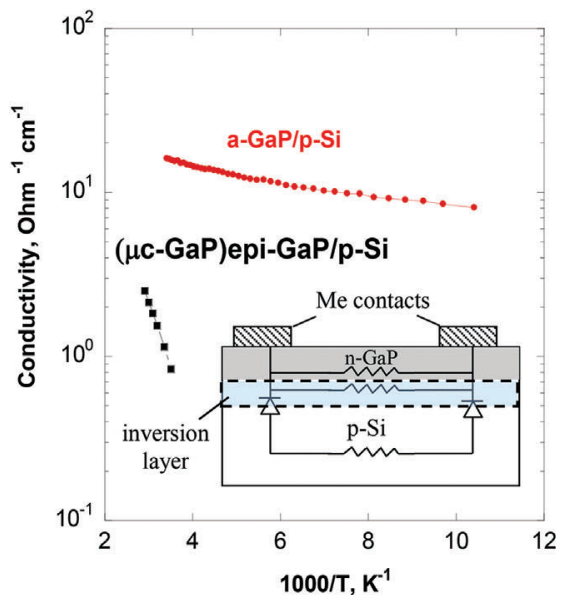

(a)

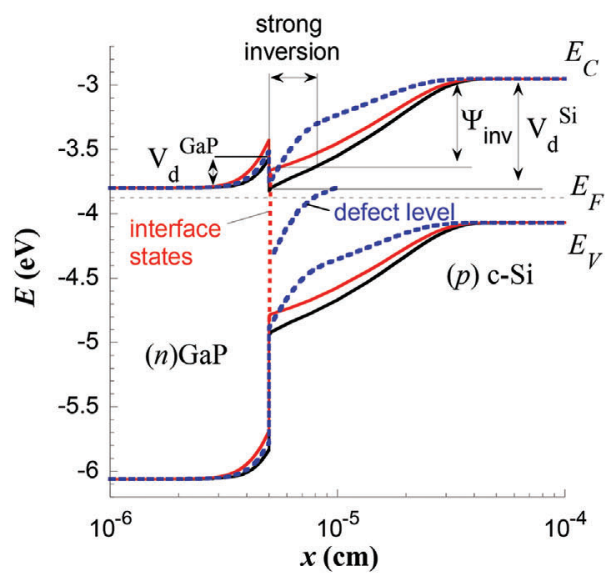

(b)

Figure 5. Lateral conductivity (a) and simulated equilibrium band diagram (b) for $n-G a P / p-S i$ heterostructures without defect states (black line), with interface states of $5 \times 10^{12} \mathrm{~cm}^{-2} \mathrm{eV}^{-1}$ (red line) and with defect level of $5 \times 10^{17} \mathrm{~cm}^{-3}$ in Si near the interface (blue line). Equivalent circuit for lateral conductivity is presented in the insert. The definition of $V_{d}{ }^{G a P}, V_{d}{ }^{S i}, \Psi_{\text {inv }}$ and region of strong inversion are indicated for the band diagram without defect states.

formation of an inversion layer in Si near to the $\mathrm{GaP} / \mathrm{Si}$ interface due to strong band bending. ${ }^{[17]}$ The formation of this layer with a high electron concentration near the interface in $\mathrm{Si}$ was confirmed by Hall measurements. High electron sheet concentration $\left(1-9 \times 10^{13} \mathrm{~cm}^{-2}\right)$ and mobility of $20-225 \mathrm{~cm}^{2} \mathrm{~V}^{-1} \mathrm{~s}^{-1}$ were obtained. Similarly for $\mathrm{n}-\mathrm{GaP} / \mathrm{p}-\mathrm{Si}$ heterostructures with epi-GaP obtained without hydrogen plasma an inversion layer was detected by Hall measurements with electron sheet concentration of $2.5 \times 10^{12} \mathrm{~cm}^{-2}$ and mobility of about $70 \mathrm{~cm}^{2} \mathrm{~V}^{-1} \mathrm{~s}^{-1}$.

However, in case of epitaxial $\mathrm{GaP}$ at the interface obtained with hydrogen plasma the lateral conductivity is more than order of magnitude lower compared to that of the amorphous interface and has stronger temperature dependence with activation energy of $0.16 \mathrm{eV}$ (Figure 3a). In this case Hall measurements can not be performed using our standard equipment due to the low conductivity. Moreover, $I-V$ curves measured between two planar electrodes exhibit non linear dependence indicating rather conductance of reverse biased diodes, which are connected in series (see inset of Figure 5a). In this case, the conductance via the $\mathrm{p}$-Si substrate dominates over the conductance via the inversion layer. Low conductivity of the inversion layer could be related to lower mobility or lower electron concentration in case of the epi-GaP interface. A decrease of both values may be explained in terms of defect states.

In fact the presence of the inversion layer indicates a strong band bending in Si. For the structures with epi-GaP interface fabricated with hydrogen plasma a high defect density is expected to be located at the interface or in Si near to the surface. Defect states could lead to pinning of the Fermi level at the position closer to the valence band and therefore lower electron concentration in the inversion layer. An effect of the Fermi level pinning at the $\mathrm{GaP} / \mathrm{Si}$ interface at $1.5 \mathrm{eV}$ above the valence band was reported in ref. [3] where further annealing provides a shift of the Fermi level position toward the conductance band. The band diagram at equilibrium was simulated for the $n-\mathrm{GaP} / \mathrm{p}-\mathrm{Si}$ heterojunction with interface states density $\left(D_{\mathrm{it}}\right)$ of $5 \times 10^{12}$ $\mathrm{cm}^{-2} \mathrm{eV}^{-1}$ and without $\mathrm{D}_{\text {it }}$ using AFOR-HET ${ }^{[18]}$ software (Figure $5 b$ ). The density of interface states was taken as constant through the bandgap, assuming donor/acceptor-like defects in the lower/upper half of the bandgap. Doping concentration of $N_{\mathrm{d}}=10^{18} \mathrm{~cm}^{-3}$ and $N_{\mathrm{a}}=10^{16} \mathrm{~cm}^{-3}$ for $\mathrm{n}-\mathrm{GaP}$ and $\mathrm{p}-\mathrm{Si}$, respectively, and $\Delta E_{\mathrm{V}}=0.9 \mathrm{eV}$ were used. Without interface states a strong inversion layer leading to high electron concentration, up to $6 \times 10^{18} \mathrm{~cm}^{-3}$, occurs in Si near to the $\mathrm{GaP} / \mathrm{Si}$ interface. Introduction of a high interface states density $\left(5 \times 10^{12} \mathrm{~cm}^{-2} \mathrm{eV}^{-1}\right)$ leads to a shift of the Fermi level toward midgap due to the pining effect. Band bending in Si decreases sufficiently so that strong inversion at the interface disappears (electron concentration $<10^{16} \mathrm{~cm}^{-3}$ ). A similar effect occurs when a high defect density is introduced in Si near to the interface. We calculated the band diagram for an acceptor like point defect located in the middle of the Si bandgap $\left(E_{\mathrm{t}}=0.56\right.$ $\mathrm{eV)}$ with a concentration of $5 \times 10^{17} \mathrm{~cm}^{-3}$ that was introduced within a region of $50 \mathrm{~nm}$ from the $\mathrm{GaP} / \mathrm{Si}$ interface. This is presented in Figure 5b. Significant decrease of the electron concentration underneath the Si surface can be also observed. Obviously the defect density could also affect the electron mobility. Thus high density of states at the GaP/Si interface or in the subsurface region can lead to lower lateral conductivity. However, the calculated values of $V_{\mathrm{OC}}$ are quite different for $n$ $\mathrm{GaP} / \mathrm{p}$-Si structures where defects are located at the interface or in the subsurface region if the same capture cross section value $\left(\sigma_{\mathrm{n}}=\sigma_{\mathrm{p}}=10^{-13} \mathrm{~cm}^{2}\right)$ for hole and electron is considered. The structure with interface defect density $\left(5 \times 10^{12} \mathrm{~cm}^{-2} \mathrm{eV}^{-1}\right)$ exhibits a $V_{\mathrm{OC}}$ value of $0.44 \mathrm{~V}$ under AM1.5 illumination. In contrast, a value of $0.21 \mathrm{~V}$ was calculated for the structure with defects $\left(5 \times 10^{17} \mathrm{~cm}^{-3}\right)$ located in a region of $50 \mathrm{~nm}$ near to the 
interface. This strong difference in photovoltaic properties for the structures with similar potential drop in Si could be used for the analysis of experimental data.

One direct method to get insight into the potential drop in abrupt $\mathrm{p}-\mathrm{n}$ heterojunctions is to use $C-V$ measurements. ${ }^{[19]}$ Conventionally the intercept of $1 / \mathrm{C}^{2}$ curve with the voltage axis $\left(V_{\text {int }}\right)$ gives an estimation of the total diffusion potential which is the sum of the diffusion potential in $\mathrm{Si}\left(V_{\mathrm{d}}{ }^{\mathrm{Si}}\right)$ and in $\mathrm{GaP}\left(V_{\mathrm{d}}^{\mathrm{GaP}}\right)$. However, in case where the inversion layer is formed at the interface the contribution to this intercept value from the Si part is limited by the potential drop in the depletion region $\left(\Psi_{\text {inv }}\right)$ only. ${ }^{[20]}$ The measured $1 / \mathrm{C}^{2}$ curves versus voltage at high frequency $(100 \mathrm{kHz})$ for the heterojunctions with both a-GaP interface (a-GaP and $\mu \mathrm{c}-\mathrm{GaP}$ layers) and epi-GaP interface formed using a hydrogen plasma step are presented in Figure 6 . The curves are linear with approximately the same slope and intercept voltage $\left(V_{\text {int }}\right)$. Linear behavior indicates a constant doping concentration profile within the depletion region variation range $(0.3-0.8 \mu \mathrm{m})$ suggesting that there is no hydrogen plasma induced $\mathrm{B}$ passivation ${ }^{[21]}$ in this range. The slope for all the samples gives a value for the doping concentration of $10^{16} \mathrm{~cm}^{-3}$ which is in agreement with the $\mathrm{Si}$ wafer resistivity. The value of $V_{\text {int }}(\approx 0.85 \mathrm{~V})$ is the same for all the samples. According to the estimation from the calculated band diagram (Figure $5 \mathrm{~b}$ ), $V_{\text {int }}$ is obviously limited by the potential drop in the depletion region $\left(\Psi_{\text {inv }}\right)$. It means that even for the structure with the epi-GaP interface produced with hydrogen plasma $V_{\mathrm{d}}^{\mathrm{Si}}$ should be larger than or equal to $\Psi_{\text {inv }}$. Thus taking into account the doping level of $\mathrm{p}$-Si and estimated values for the doping level in $\mathrm{n}-\mathrm{GaP}\left(>10^{18} \mathrm{~cm}^{-3}\right)$ the position of the Fermi level at the interface for all the structures could be estimated to be in the range of $0.85-1.05 \mathrm{eV}$ above the valence band of $\mathrm{Si}$.

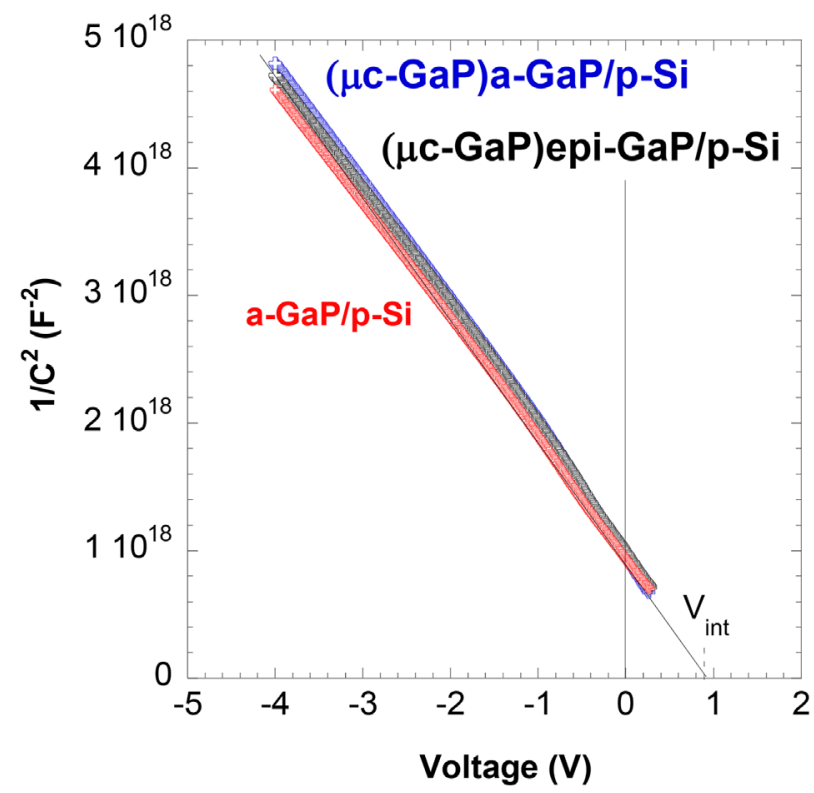

Figure 6. High frequency $(100 \mathrm{kHz}) 1 / \mathrm{C}^{2}$ curves versus voltage for $n-G a P /$ $\mathrm{p}$-Si heterostructures with a-GaP (a-GaP and $\mu \mathrm{c}-\mathrm{GaP}$ layer) and epi-GaP interfaces measured at room temperature.
Interface states as well as defect levels in the volume of the semiconductors could be directly detected by admittance spectroscopy (C-T- $\omega$ and G-T- $\omega) \cdot{ }^{[22,23]}$ If the Fermi level in the space charge region of the junction crosses the trap level a small variation of the ac voltage implying a variation of the Fermi level can lead to a change of charge and contribute to the capacitance, provided the frequency of the test signal is low enough for capture/emission of the charge carriers into/from the trap level to occur. In contrast, at high frequency the states occupancy cannot follow the ac change of the Fermi level. So, there is a transition angular frequency $\left(\omega_{0}\right)$ that corresponds to the emission rate, which is proportional to $\exp \left(-E_{\mathrm{t}} / k T\right)$, where $E_{\mathrm{t}}$ is the difference between the trap level and the nearest band. Thus the temperature dependence of $\omega_{0}$ allows one to determine the energy of the trap level. Experimentally $\omega_{0}$ can be determined by the maximum of $d C / d \omega$ or by a peak in $G / \omega, G$ being the related conductance. Thus an Arrhenius plot of $\omega_{0}$ can be used to determine an activation energy that corresponds to $E_{t}$.

In case of the $n-G a P / p-S i$ heterojunction, the overall capacitance may be defined by the equivalent circuit presented in the insert of Figure 7. $C_{\mathrm{w}} \mathrm{GaP}$ and $C_{\mathrm{w}} \mathrm{Si}$ are the capacitances of the depleted regions in $\mathrm{GaP}$ and $\mathrm{Si}$, respectively. An additional capacitance, $C_{\mathrm{t}}^{\mathrm{GaP}}$, being in parallel to $C_{\mathrm{w}}{ }^{\mathrm{GaP}}$ is related to the electron exchange between $\mathrm{n}-\mathrm{GaP}$ and interface states/defects in $\mathrm{GaP}$. In the same way, an additional capacitance, $C_{\mathrm{t}}^{\mathrm{c}-\mathrm{Si}}$, in parallel to $C_{\mathrm{w}}{ }^{\mathrm{Si}}$, is related to the exchange of holes between $\mathrm{p}$-Si and states located at the interface or in the space charge region in Si. The capacitance of the very thin depletion region in $\mathrm{GaP}\left(C_{\mathrm{w}}^{\mathrm{GaP}}\right)$ is expected to be large so that the overall capacitance should be more sensitive to the silicon side since both $C_{\mathrm{w}}{ }^{\mathrm{GaP}}$ and $C_{\mathrm{t}}^{\mathrm{GaP}}$ are connected in series with the capacitances of the Si side (insert of Figure 7a). Additionally, a temperature-dependent conductance $G^{\mathrm{GaP}}$, which is related to the transport activation through a spike of $E_{\mathrm{C}}$ at the $\mathrm{GaP} / \mathrm{Si}$ interface (Figure 7a), should be taken into account. ${ }^{[24]}$ Thermal activated electron transport over this barrier leads to the shunting of $C_{\mathrm{w}}$ GaP , which also makes the overall capacitance more sensitive to the silicon side and increase toward the sum of $\mathrm{C}_{\mathrm{w}}^{\mathrm{Si}}$ and $\mathrm{C}_{\mathrm{t}}^{\mathrm{c}-\mathrm{Si}}$.

Variations of the capacitance response $C_{\mathrm{t}}^{\mathrm{c}-\mathrm{Si}}$ with the applied $\mathrm{dc}$ bias allows one to distinguish the response of interface states from that of states located in the space charge region. Indeed, if at zero bias $C_{\mathrm{t}}^{c-\mathrm{Si}}$ is caused by the response from interface states (exchange of holes) the corresponding activation energy should be equal to the difference $E_{\mathrm{F}}-E_{\mathrm{V}}{ }^{\mathrm{Si}}$ at the interface. When a positive bias voltage is applied to the heterojunction one has to consider the quasi Fermi level for holes, $E_{\mathrm{Fp}}$, and the activation energy for the exchange of holes between interface states and $p$ $\mathrm{Si}$ is then equal to the value of $E_{\mathrm{Fp}}-E_{\mathrm{V}}{ }^{\mathrm{Si}}$ at the interface, which should be lower than that of $E_{\mathrm{F}}-E_{\mathrm{V}}{ }^{\mathrm{Si}}$ (Figure 7b). Thus the change of the activation energy with positive applied bias is a sign of the interface states response. However, if the response is related to a defect level in the space charge region of $\mathrm{Si}$ the activation energy should correspond to $E_{\mathrm{t}}$ and be independent of the applied dc bias (Figure 7b).

The experimental admittance spectra at zero bias for both heterojunctions with a-GaP and epi-GaP fabricated with hydrogen plasma are presented in Figure 8. A small step with limited amplitude is observed in the temperature range $200-340 \mathrm{~K}$ for both structures. This step is related to either the 


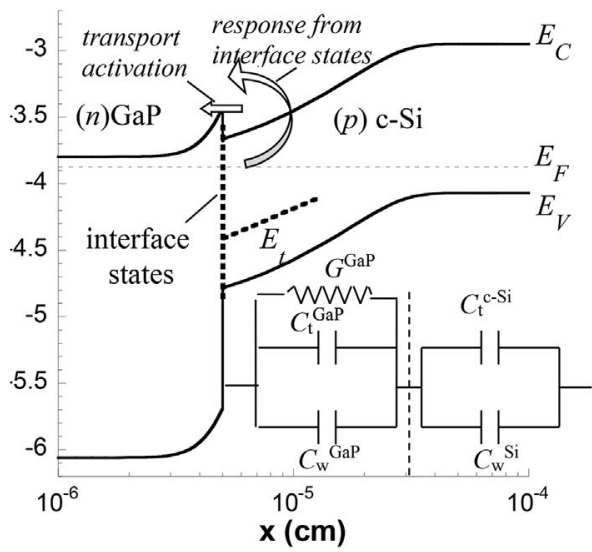

(a)

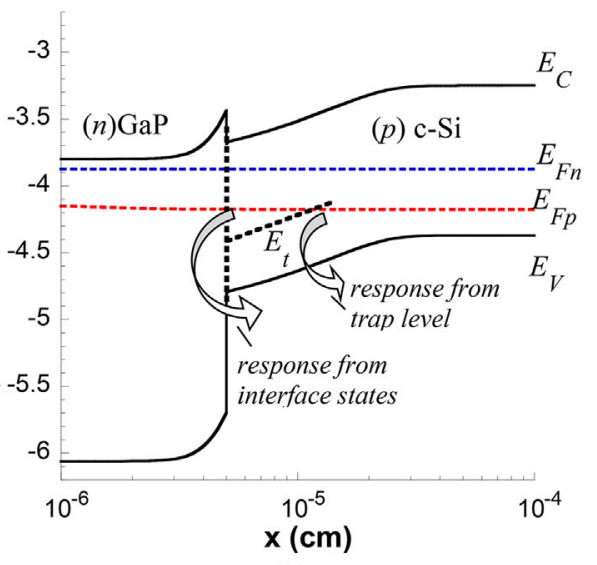

(b)

Figure 7. Calculated band diagram for $n-G a P / p-S i$ heterostructures at $0 \mathrm{~V}$ (a) and at direct bias of $0.3 \mathrm{~V}$ (b). Equivalent circuit for the capacitance is presented in the insert.

electron exchange between $\mathrm{n}-\mathrm{GaP}$ and interface states/defects in $\mathrm{GaP}\left(C_{\mathrm{t}}^{\mathrm{GaP}}\right)$ or transport activation over a barrier at the $\mathrm{GaP} / \mathrm{Si}$ interface. Both spectra do not exhibit any response related to the exchange of holes between $\mathrm{p}$-Si and states located at the interface as well as in the space charge region in $\mathrm{Si}\left(C_{\mathrm{t}}^{\mathrm{Si}}\right)$. This was expected because the estimated activation energy from the position of the Fermi level $(0.85-1.05 \mathrm{eV})$ is too large to be detected in the experimental range of frequency and temperature.

When the positive bias of $0.3 \mathrm{~V}$ is applied, the structure with aGaP does not demonstrate any additional response (Figure 9a). The capacitance measurements above $300 \mathrm{~K}$ become noisy and not reliable because of drastic rise of the conductivity of direct biased junction. However, a strong response is observed for the structure with the epi-GaP interface produced with hydrogen plasma (Figure 9b). Significant increase of the capacitance above $240 \mathrm{~K}$ corresponds to the contribution of $C_{\mathrm{t}} \mathrm{Si}$ related to holes exchange between $\mathrm{p}$-Si and defect states. The determined activation energy of $0.33 \pm 0.02 \mathrm{eV}$ is significantly lower compared to the estimated position of $E_{\mathrm{Fp}}$ at the interface
$(0.55-0.75 \mathrm{eV})$ for $0.3 \mathrm{~V}$ direct bias. Moreover, the activation energy does not depend on applied voltage in the range of $0.2-$ $0.4 \mathrm{~V}$. Thus the detected response is rather related to the trap level in $\mathrm{Si}$. On the other hand no response was observed at zero bias while it should be detected because the Fermi level in the quasi neutral region of $\mathrm{p}-\mathrm{Si}\left(0.18-0.2 \mathrm{eV}\right.$ above $\left.E_{\mathrm{V}}\right)$ for the temperature range of the measurements crosses the trap level $(0.33 \mathrm{eV})$ in the space charge region at the distance of $0.15-0.2 \mu \mathrm{m}$ from the interface. This discrepancy could be explained by the fact that defects are located in $\mathrm{Si}$ only near to the $\mathrm{GaP} / \mathrm{Si}$ interface within a distance of $30-50 \mathrm{~nm}$ (Figure $5 \mathrm{~b}$ ). In this case at equilibrium the Fermi level does not cross $E_{\mathrm{t}}$ while when a direct voltage $(>0.2 \mathrm{~V})$ is applied $E_{\mathrm{Fp}}$ can cross $E_{\mathrm{t}}$ and a response in admittance spectra is observed. The capacitance signal increases with direct bias indicating an increase of the defect density toward the interface.

The presence of a defect rich region in $\mathrm{Si}$ near the $\mathrm{GaP} / \mathrm{Si}$ interface has been confirmed by TEM studies. TEM cross section images for $\mu \mathrm{c}-\mathrm{GaP} / \mathrm{Si}$ structures with a-GaP and epi-GaP interfaces are presented in Figure 10. For epi-GaP interfaces fabricated with hydrogen plasma a damaged region of the $\mathrm{Si}$

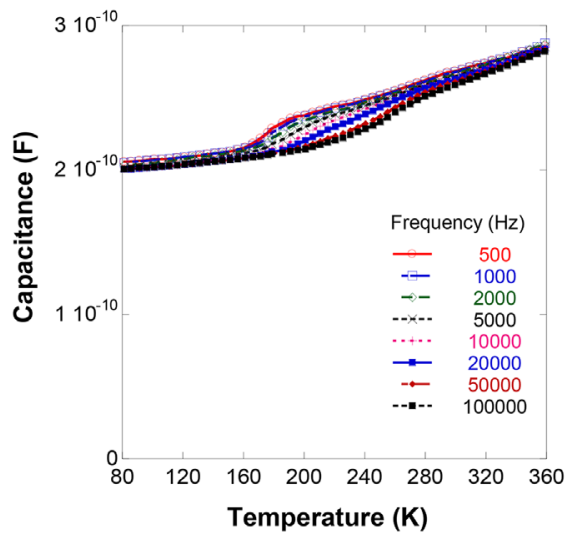

(a)

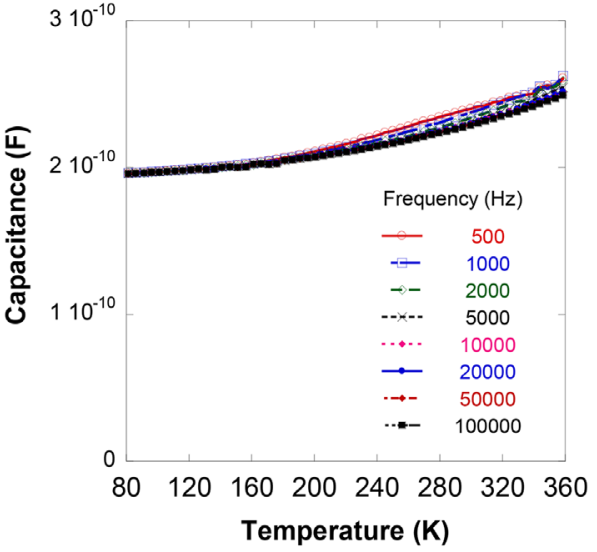

(b)

Figure 8. C-T-f at $\mathrm{OV}$ for $\mathrm{GaP} / \mathrm{Si}$ structures with a-GaP (a) and epi-GaP (b) interfaces grown using hydrogen plasma. 


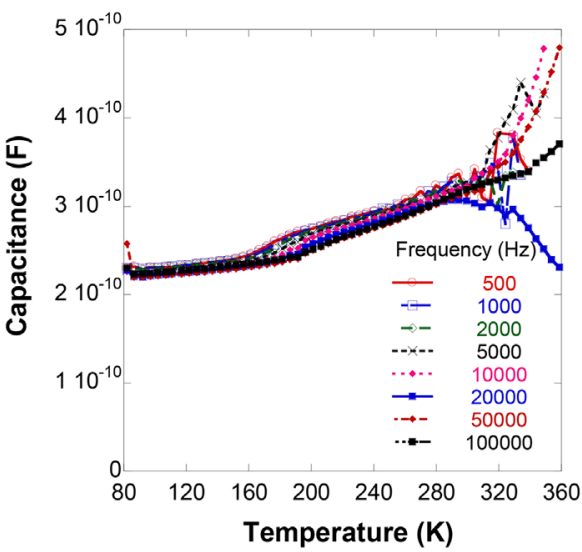

(a)

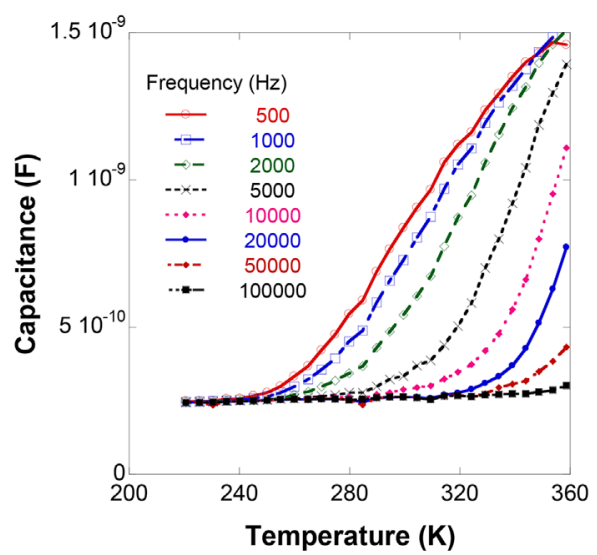

(b)

Figure 9. C-T-f at $0.3 \vee$ for GaP/Si structures with a-GaP (a) and epi-GaP (b) interfaces grown using hydrogen plasma.

substrate within $\approx 30 \mathrm{~nm}$ could be clearly identified in bright and dark field contrast (Figure 10c and d). In case of the a-GaP interface (Figure 10a and b) and epi-GaP interface fabricated without hydrogen plasma (Figure 10e and $\mathrm{f}$ ), this damaged area is not observed.

\section{Discussions}

For $\mathrm{GaP}$ grown on $\mathrm{Si}$, the barrier formed by the significant valence band offset $(0.8-1 \mathrm{eV})$ blocks the transport of the holes from $\mathrm{p}$-Si to $\mathrm{n}-\mathrm{GaP}$ limiting recombination losses in $\mathrm{GaP}$ layer and top contact. In this case only defects located at the $\mathrm{GaP} / \mathrm{Si}$ interface and in Si could affect the recombination. Admittance spectroscopy detected a small step, which is related to either the electron exchange between $\mathrm{n}-\mathrm{GaP}$ and interface states or transport activation over a barrier at the $\mathrm{GaP} / \mathrm{Si}$ interface. The bias dependence does not allow us to distinguish between the two cases. The position of $E_{\mathrm{Fn}}$ at the $\mathrm{GaP} / \mathrm{Si}$ interface does not depend on applied bias due to the strong doping of $n-G a P$. However, for the a-GaP/Si structure the activation energy $\left(E_{\mathrm{a}}\right)$ being about $0.3 \mathrm{eV}$ indicates that the response should rather arise from interface states, which becomes detectable for $D_{\text {it }}>10^{12}$ $\mathrm{cm}^{-2} \mathrm{eV}^{-1}$. In this case $E_{\mathrm{a}}$ corresponds well to the difference $E_{\mathrm{C}}{ }^{\mathrm{GaP}}-E_{\mathrm{F}}$ at the $\mathrm{GaP} / \mathrm{Si}$ interface. On the contrary, for the epi$\mathrm{GaP}$ sample, $E_{\mathrm{a}}$ being about $0.1 \mathrm{eV}$ corresponds rather to the effective potential barrier height at the $\mathrm{GaP} / \mathrm{Si}$ interface, which is related to $\Delta E_{\mathrm{C}}$. Thus lower interface states density is expected for epi-GaP/Si interface.

Concerning the defects located in Si space charge region, no response was detected for the sample with a-GaP/Si interface. On the contrary, the admittance measurements for epi-GaP/c-Si grown using hydrogen plasma reveal the presence of a high defect density (about $10^{17} \mathrm{~cm}^{-3}$ ) in the subsurface region of $\mathrm{Si}$ within a distance of $30-50 \mathrm{~nm}$ from the interface. The trap level with position of $E_{\mathrm{V}}+(0.33 \pm 0.02) \mathrm{eV}$ detected by admittance spectroscopy could be related to carbon-related complexes $\mathrm{C}_{\mathrm{i}}-\mathrm{O}_{\mathrm{i}}$ $\left(E_{\mathrm{V}}+0.35 \mathrm{eV}\right)$, which was observed in B-doped Si substrates after electron irradiation. ${ }^{[25-27]}$ In ref. [28] the defect level of $E_{\mathrm{V}}$ $+0.34 \mathrm{eV}$ was associated with Ga-related defects. However, the defect level of the same position $\left(E_{\mathrm{V}}+0.34 \mathrm{eV}\right)$ detected in $\mathrm{Ga}$ doped $\mathrm{Si}$ was also attributed to the $\mathrm{C}_{\mathrm{i}}-\mathrm{O}_{\mathrm{i}}$ complex. ${ }^{[29-33]}$ These defects are mostly observed in electron-irradiated damaged Si.

Damage of $\mathrm{Si}$ in the subsurface region within the distance similar to that estimated by admittance spectroscopy $(30 \mathrm{~nm})$ has also been revealed by TEM for the epi-GaP/Si structure fabricated with hydrogen plasma. This damaged area provides a strong recombination loss leading to drastic reduction of the photovoltaic performance that invalidates the advantages of low temperature technology. The $C-V$ measurements demonstrate a relatively high band bending in $\mathrm{Si}$ and predict high electron concentration near the interface for all the samples including one with epi-GaP/Si grown with hydrogen plasma. Thus the lower lateral conductivity observed for the latter sample is rather related to the reduction of electron mobility in the damaged area.

The origin of the defects is a key issue for further technology development. The defects in Si are obviously caused by high power hydrogen plasma treatment, which occurs during the whole $\mu \mathrm{c}-\mathrm{GaP}$ growth process. When growth of $\mu \mathrm{c}-\mathrm{GaP}$ was realized by a new PE-ALD process without hydrogen plasma the damage of $\mathrm{Si}$ in the near surface region was not observed indicating at least lower concentration of the defects. There are different mechanisms, which could be involved in defect creation: deep UV radiation of plasma discharge, electron or particle bombardment (ions and neutrals) ${ }^{[34]}$ as well as hydrogen incorporation in $\mathrm{Si}$.

We should stress that similar effects of hydrogen plasma of comparable power density on Si subsurface region was observed for a-Si:H/c-Si heterojunctions in ref. [13]. Complete removing of the a-Si:H layer by hydrogen plasma etching lead to a decrease of effective lifetime in $\mathrm{Si}$ accompanied by an increase in the c-Si surface roughness and the appearance of defects in the nearsurface $(10-15 \mathrm{~nm})$ crystalline structure observed by TEM. However, it was enough to leave a thin $(8 \mathrm{~nm})$ a-Si:H layer to shield the c-Si surface from sub-surface defect creation. The same protective properties of thin a-GaP layer were demonstrated in our work. The damage of Si was observed neither by TEM nor from photoelectrical measurements when thin (about $5 \mathrm{~nm}$ ) a-GaP layer was grown on Si prior to $\mu \mathrm{c}-\mathrm{GaP}$ growth with high power hydrogen plasma. This layer seems to be too thin to 


\section{ADVANCED
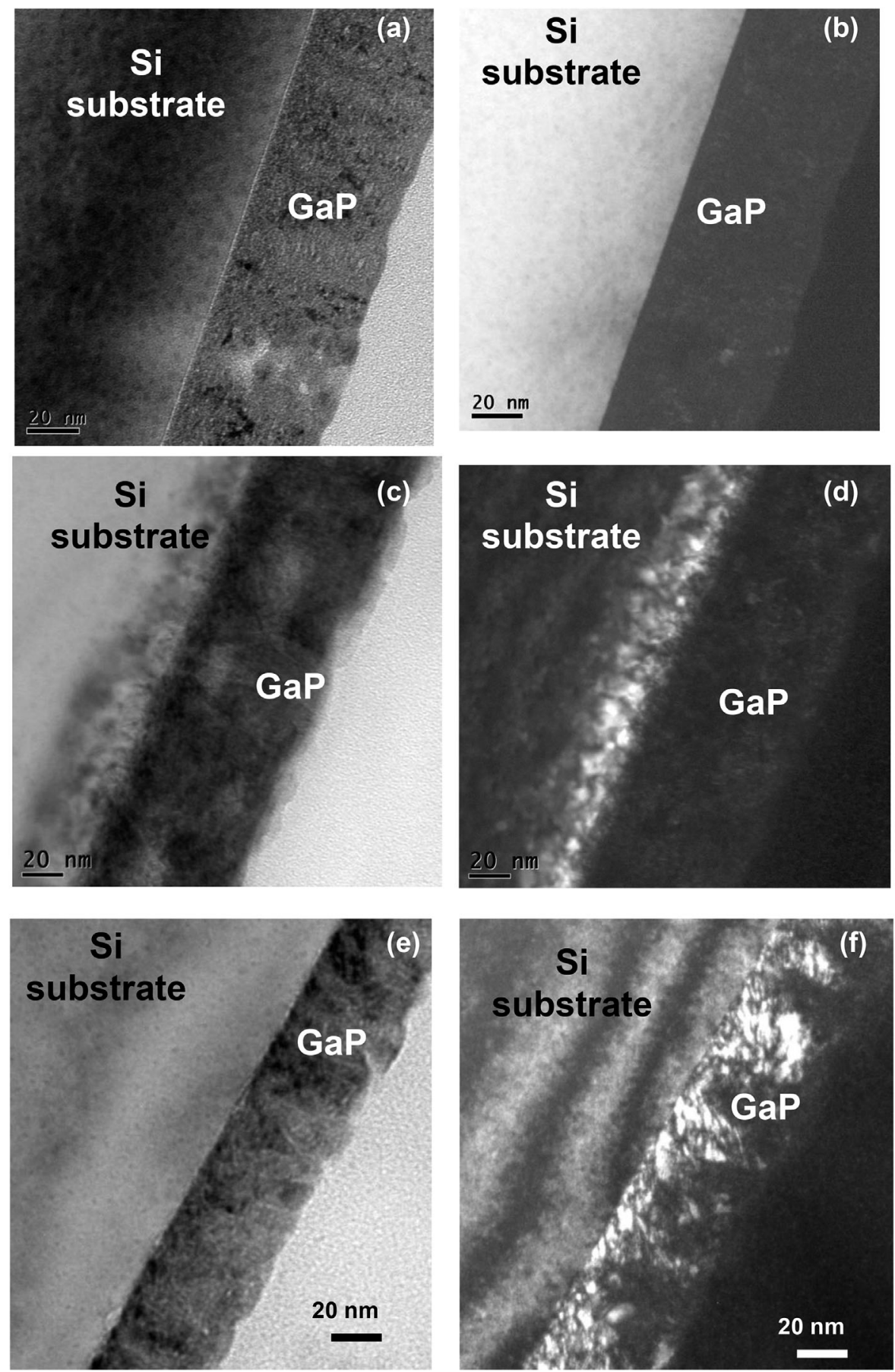

Figure 10. TEM cross section view in bright (a, $c$, and e) and dark field (b, $d$, and f) contrast for GaP/Si structures with a-GaP (a and b) and epi-GaP interfaces ( $c$ and $d$ ) fabricated with hydrogen plasma and epi-GaP produced without hydrogen plasma (e and $f$ ).

protect from UV irradiation and hydrogen diffusion, while it seems to be enough to avoid direct interaction of the Si surface with hydrogen plasma.

Thus the most important result for further technology development of high quality epitaxial growth of $\mathrm{GaP}$ on $\mathrm{Si}$ substrate by PE-ALD is that hydrogen plasma plays a crucial role that should be taken into account.

\section{Conclusion}

Electronic properties of $\mathrm{n}-\mathrm{GaP} / \mathrm{p}$-Si heterojunctions with a-GaP or $\mu \mathrm{c}-\mathrm{GaP}$ grown by PE-ALD under different conditions were studied using a set of space charge capacitance techniques and conventional photoelectrical measurements. In case of continuous hydrogen plasma, the growth of amorphous GaP at low RF 
power provides better photovoltaic performance of the a-GaP/Si interface compared to the interface with thin $(3 \mathrm{~nm})$ epitaxial $\mathrm{GaP}$ fabricated at high RF power. When the deposition started by growth of thin epitaxial $\mathrm{GaP}$ layer using hydrogen plasma a defect rich area with a hole trap level $E_{\mathrm{V}}+(0.33 \pm 0.02) \mathrm{eV}$ was detected in Si within $30-50 \mathrm{~nm}$ near to the GaP/Si interface by admittance spectroscopy. The damaged area in Si within the same distance from the interface was also observed by TEM. The damage of $\mathrm{Si}$ is related to the interaction of hydrogen plasma with the Si surface during the deposition process. When a thin $(5 \mathrm{~nm})$ amorphous GaP layer deposited prior to $\mu \mathrm{c}-\mathrm{GaP}$ grown with hydrogen plasma or epitaxial growth of $\mathrm{GaP}$ was realized by a new PE-ALD process without hydrogen plasma the damage of $\mathrm{Si}$ in the sub-surface region was not observed. Lower concentration of defects in this case is also correlated to higher photovoltaic performance of those samples. Further study of the $\mathrm{GaP} / \mathrm{Si}$ hetero-interface properties obtained by hydrogen plasma free PE-ALD process will be performed in the future.

\section{Acknowledgments}

Experimental work was supported by the Russian Scientific Foundation under grant number 17-19-01482 and theoretical study was supported by CNRS under the research project PRC "PacSific" no. 1062.

\section{Conflict of Interest}

The authors declare no conflict of interest.

\section{Keywords}

admittance spectroscopy, GaP/Si heterojunction, interface, PE-ALD, solar cells

Received: July 31, 2018

Revised: October 18, 2018

Published online: December 18, 2018

[1] C. Huang, L. Ye, X. Wang, J. Phys.: Condens. Matter 1989, 1, 907.

[2] O. Romanyuk, T. Hannappel, F. Grosse, Phys. Rev. B 2013, 88, 115312.

[3] P. Perfetti, F. Patella, F. Sette, C. Quaresima, C. Capasso, A. Savoia, G. Margaritondo, Phys. Rev. B 1984, 30, 4533.

[4] A. D. Katnani, G. Margaritondo, Phys. Rev. B 1983, 28, 1944.

[5] I. Sakata, H. Kawanami, Appl. Phys. Express 2008, 1, 91201.

[6] A. S. Gudovskikh, K. S. Zelentsov, A. I. Baranov, D. A. Kudryashov, I. A. Morozov, E. V. Nikitina, J.-P. Kleider, Energy Procedia 2016, 102, 56.
[7] E. García-Tabarés, I. Rey-Stolle, Sol. Energy Mater. Sol. Cells 2014, 124, 17.

[8] R. Varache, M. Darnon, M. Descazeaux, M. Martin, T. Baron, D. Muñoz, Energy Procedia 2015, 77, 493.

[9] . L. Ding, C. Zhang, T. U. Nærland, N. Faleev, C. Honsberg, M. I. Bertoni, Energy Procedia 2016, 92, 617.

[10] M. Feifel, T. Rachow, J. Benick, J. Ohlmann, S. Janz, M. Hermle, F. Dimroth, D. Lackner, IEEE J. Photovolt. 2016, 6, 384.

[11] A. S. Gudovskikh, I. A. Morozov, A. V. Uvarov, D. A. Kudryashov, E. V. Nikitina, A. S. Bukatin, V. N. Nevedomskiy, J.-P. Kleider, J. Vac. Sci. Technol. A 2018, 36, 21302.

[12] G. G. DeLeo, Physica B 1991, 170, 295.

[13] J. Geissbuhler, S. De Wolf, B. Demaurex, J. P. Seif, D. T. L. Alexander, L. Barraud, C. Ballif, Appl. Phys. Lett. 2013, 102, 231604.

[14] A. I. Baranov, A. S. Gudovskikh, D. A. Kudryashov, I. A. Morozov, A. M. Mozharov, E. V. Nikitina, K. S. Zelentsov, A. Darga, S. Le Gall, J.-P. Kleider, Phys. Status Solidi A 2017, 214, 1700685.

[15] A. Ishizaka, Y. Shiraki, J. Electrochem. Soc. 1986, 133, 666.

[16] A. I. Baranov, I. A. Morozov, A. V. Uvarov, G. E. Yakovlev, J.-P. Kleider, J. Phys.: Conf. Ser. 2018, 1124. in press.

[17] A. S. Gudovskikh, A. V. Uvarov, I. A. Morozov, A. I. Baranov, D. A. Kudryashov, E. V. Nikitina, A. A. Bukatin, K. S. Zelentsov, I. S. Mukhin, A. Levtchenko, S. Le Gall, J.-P. Kleider, J. Renew. Sustain. Energy 2018, 10, 21001.

[18] R. Varache, C. Leendertz, M. E. Gueunier-Farret, J. Haschke, D. Muñoz, L. Korte, Sol. Energy Mater. Sol. Cells 2015, 141, 14.

[19] S. R. Forrest, in Heterojunction Band Discontinuities (Eds: F. Capasso, G. Margaritondo), North-Holland, Amsterdam 1987, pp. 311-375.

[20] A. S. Gudovskikh, S. Ibrahim, J.-P. Kleider, J. Damon-Lacoste, P. Roca i Cabarrocas, Y. Veschetti, P.-J. Ribeyron, Thin Solid Films 2007, 515, 7481.

[21] C. Sah, J. Y. Sun, J. J. Tzou, Appl. Phys. Lett. 1983, 43, 204.

[22] D. V. Lang, J. D. Cohen, J. P. Harbison, Phys. Rev. B 1982, 25, 5285.

[23] D. L. Losee, J. Appl. Phys. 1975, 46, 2204.

[24] A. S. Gudovskikh, J. P. Kleider, R. Chouffot, N. A. Kalyuzhnyy, S. A. Mintairov, V. M. Lantratov, J. Phys. D: Appl. Phys. 2009, 42, 165307.

[25] M. Yamaguchi, A. Khan, T. K. Vu, Y. Ohshita, T. Abe, Physica B 2003, 340-342, 596.

[26] M. Mamor, M. Willander, F. D. Auret, W. E. Meyer, E. Sveinbjörnsson, Phys. Rev. B 2000, 63, 45201.

[27] F. D. Auret, P. N. K. Deenapanray, Crit. Rev. Solid State Mater. Sci. 2004, 29, 1.

[28] H. M. DeAngelis, P. J. Drevinsky, Appl. Phys. Lett. 1983, 42, 613.

[29] A. Khan, M. Yamaguchi, Y. Ohshita, N. Dharmarasu, K. Araki, T. Abe, H. Itoh, T. Ohshima, M. Imaizumi, S. Matsuda, J. Appl. Phys. 2001, 90, 1170.

[30] A. Khan, M. Yamaguchi, T. Hisamatsu, S. Matsuda, J. Appl. Phys. 2000, 87, 2162.

[31] J. M. Trombetta, G. D. Watkins, MRS Proc. 1987, 104, 93.

[32] Y. Tokuda, H. Sato, Mater. Sci. Semicond. Process. 2003, 6, 277.

[33] P. M. Mooney, L. J. Cheng, M. Süli, J. D. Gerson, J. W. Corbett, Phys. Rev. B 1977, 15, 3836.

[34] A. Plagemann, K. Ellmer, K. Wiesemann, J. Vac. Sci. Technol. A 2007, $25,1341$. 